\title{
Morfología de plántulas de Bursera JacQ. ex L. (Burseraceae) Y SUS IMPLICACIONES FILOGENÉTICAS
}

\author{
Agustina Rosa Andrés-Hernández y David Espinosa-Organista \\ Herbario de la Facultad de Estudios Superiores "Zaragoza”, UNAM. Av. Guelatao 66, Col. Ejército de Oriente, 09230 \\ Iztapalapa, D.F. México. Correo electrónico: arah@colpos.colpos.mx; \\ despinos@servidor.unam.mx
}

\begin{abstract}
Resumen: Se estudiaron caracteres de plántulas de diez especies de Bursera para encontrar nueva evidencia taxonómica. Todas las especies presentaron germinación faneroepígea. Las plántulas de especies de la sección Bursera -que incluye al 'complejo B. simaruba' (mulatos) y a los 'cuajiotes'- presentaron raíz axonomorfa engrosada en la base del cuello e hipocótilo delgado. Las hojas cotiledonares son multilobadas sólo en los 'cuajiotes' y trilobadas en las especies de 'mulatos'. Las especies de la sección Bullockia presentaron plántulas con raíz axonomorfa sin engrosamiento, hipocótilo que se vuelve engrosado, estriado y lenticelado a través de su crecimiento, y hojas cotiledonares trilobadas. Hay cuatro caracteres útiles para el análisis filogenético: (1) margen de los protófilos, (2) nervadura de los protófilos, (3) forma de las hojas cotiledonares, y (4) engrosamiento de la radícula. Los caracteres sustentan la sección Bullockia, a los 'cuajiotes' y mulatos.

Palabras clave: Bursera, plántula, morfología, México.

Abstract: Characters of seedlings from ten species of the genus Bursera were studied, in order to find additional taxonomic evidence. All species showed phanero-epigeal germination, developing a primary root system (axonomorphous root). Species included in section Bursera have a root swelling at basal level near the collar, and a slim hypocotyl. The cotyledonary leaves were multilobate in the 'cuajiotes' species group and three-lobed in species of B. simaruba complex. The species of Bursera sect. Bullockia showed a not swollen primary root system with a slim collar; a striate, lenticelled and swollen hypocotyl, and three-lobed cotyledonary leaves. There are four characters that can be considered important for phylogenetic analyses: (1) protophyll margin type, (2) protophyll venation, (3) form of cotyledonary leaves, and (4) the swolliness of the radicle. Groups like section Bullockia, the 'cuajiotes' and 'mulatos' are supported upon the distribution of characters.
\end{abstract}

Key words: Bursera, seedlings, morphology, Mexico

E 1 género Bursera Jacq. ex L. está constituido por un poco más de 100 especies. De ellas, más de 70 se distribuyen en México (Rzedowski y Kruse, 1979; Daly, 1993), principalmente en el bosque tropical caducifolio. Existe una mayor diversificación y concentración de especies endémicas sobre la vertiente del Pacífico, particularmente en la Depresión del Balsas, donde se han registrado 47 especies (Toledo-Manzur, 1982).

Engler (1883) reconoció la existencia de especies de Bursera con fruto trivalvado y otras con fruto bivalvado, y supuso que el fruto bivalvado en algunas especies de Bursera se deriva de un ovario trilocular en donde uno de los lóculos se aborta. Estos caracteres también fueron reconocidos por Bullock (1936) y con base en este patrón, McVaugh y Rzedowski (1965) propusieron dos secciones: Bursera, que incluye a todas las especies con tres valvas, y Bullockia, a las de dos valvas.

Rzedowski (1968) añadió caracteres diagnósticos para cada sección, como la presencia de catáfilos bien desarrollados en la sección Bullockia y ausentes en la sección Bursera. Por otra parte, el raquis alado de las hojas y el fruto con pseudoarilo que sólo cubre parcialmente al hueso han sido señalados como caracteres más frecuentes en Bullockia (Gillett, 1980).

Rzedowski y Kruse (1979) consideraron que el género Bursera pudo haber tenido un origen difilético, de acuerdo con la gran diferencia que hay entre sus dos secciones, así como por la afinidad que existe entre la sección Bursera y el género Boswellia y entre la sección Bullockia y el género Commiphora.

Toledo-Manzur (1982) reconoció las dos secciones y otros tres subgrupos dentro de la sección Bursera y dos dentro de la sección Bullockia. En la sección Bursera se encuentran tanto los 'mulatos', o 'complejo B. simaruba' (sensu Daly, 1993), como los 'cuajiotes rojos' y 'cuajiotes amarillos'; las especies del complejo $B$. simaruba tienen folíolos enteros, con frecuencia con el ápice acuminado y presentan hojas cotiledonares trilobadas. Los 'cuajiotes' tienen hojas 
cotiledonares multilobadas y sólo se separan por el color de su corteza. En la sección Bullockia, el primer grupo se distingue porque el pseudoarilo cubre las $2 / 3$ partes del hueso y el cáliz tiene sépalos fusionados, mientras que el segundo grupo presenta un pseudoarilo que cubre al hueso en $2 / 3$ partes o más, y un cáliz formado por sépalos libres (figura 1).

\section{Material y Métodos}

Se recolectaron semillas de 10 especies del género Bursera (apéndice 1) que se distribuyen en la Cuenca del Río Nexapa, en el sur del estado de Puebla, México. Los ejemplares de respaldo se encuentran depositados en el herbario FEZA. Las

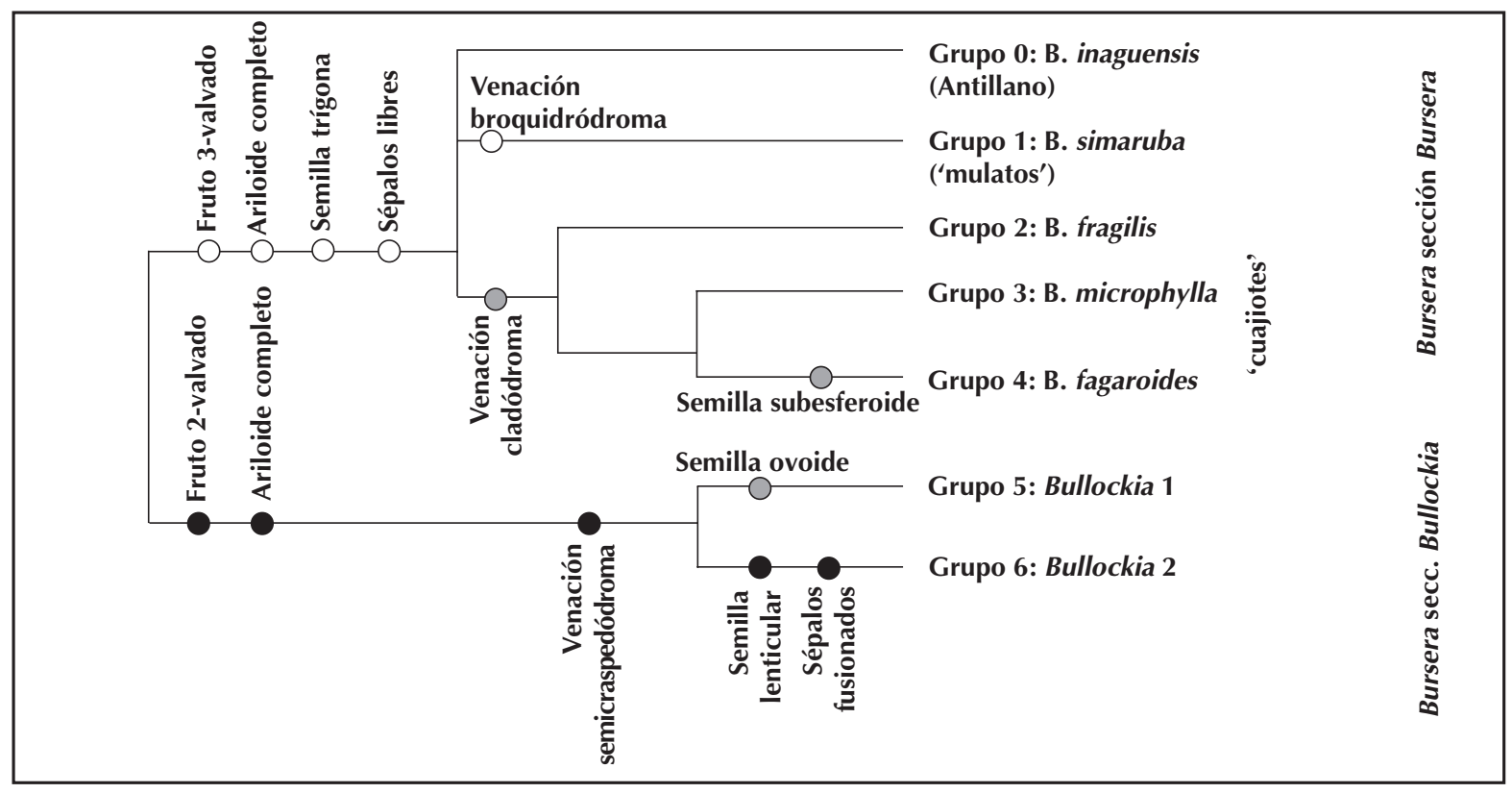

Figura 1. Estructura taxonómica de Bursera. Se combinan los grupos obtenidos para la sección Bursera obtenidos por Becerra y Venable (1999), con base en secuencias de DNA ribosomal, con los propuestos por Toledo-Manzur (1982) y Andrés-Hernández (2001), con base en caracteres morfológicos. Los estados hipotéticamente primitivos se indican en blanco y los derivados en negro (o grises y negro, según si son binarios o multiestado). El grupo antillano se coloca tentativamente en la base de la sección Bursera, aunque aún no ha sido incluido en estudios generales del género.

Los estudios sobre morfología de plántulas en el género son escasos. Sólo se han descrito superficialmente las hojas cotiledonares, mencionando si son trilobadas o multilobadas (Rzedowski y Kruse, 1979; Johnson, 1992; AndrésHernández, 1997). En Boswellia frereana Bridwood y $B$. sacra Flückiger, las hojas cotiledonares tienen cinco lóbulos (Thulin y Warfa, 1986), pero han sido descritas como multífidas. La diferencia radica en el patrón de división de los lóbulos principales de las hojas cotiledonares.

Los caracteres mencionados no han sido suficientes para esclarecer algunas complicaciones taxonómicas del género, por lo que resulta importante considerar caracteres de otros estadios de vida. Por ello abordamos el estudio morfológico de las plántulas, con el fin de explorar nuevos caracteres que contribuyan a sustentar la estructura taxonómica del grupo propuesta hasta ahora. La morfología de la plántula proporciona información valiosa no sólo para la identificación taxonómica, sino también para estudios ecológicos y para comprender su historia evolutiva. semillas se sometieron a escarificación mecánica, haciendo una incisión en la unión de las valvas para estimular la germinación. Se sembraron 100 semillas de cada especie en cajas Petri estériles, sobre papel filtro húmedo a temperatura ambiente.

La descripción de las plántulas se efectuó a partir del material biológico procedente de las pruebas de germinación y de plántulas recolectadas en campo. Se consideró como fase de plántula al periodo que transcurre desde la germinación de la semilla hasta el momento en que aparece el primer nomófilo u hoja normal. El término germinación faneroepígea -que se desarrolla sobre la superficie del suelose adopta de acuerdo con Duke y Polhill (1981). Para describir la forma de la raíz se siguieron las definiciones de Font Quer (1993); para la forma de las hojas cotiledonares se usaron los términos de Rzedowski y Kruse (1979). El término protófilo (la primera hoja que aparece inmediatamente después de las hojas cotiledonares) fue tomado de Parra (1984). Para designar la forma de los folíolos se siguieron los términos 
propuestos por Moreno (1987) y Bell (1993). La venación es referida únicamente a las venas principales según la clasificación de Hickey (1974).

Una vez reconocidos y descritos los caracteres y sus estados, se construyó una matriz de 12 caracteres. A continuación, siguiendo el criterio de Nixon y Carpenter (1993) se codificó esta matriz sin grupo externo para obtener una red de Wagner mediante el programa Hennig86 (Farris, 1988), con las restricciones de estados de carácter no ordenados (cc -) y por el procedimiento de enumeración implícita (ie*). Los caracteres fueron mapeados en la red usando el programa WINCLADA (Nixon, 1999).

\section{Resultados}

Las semillas de las especies estudiadas del género Bursera son fotoblásticas y necesitan de temperaturas elevadas (25$35^{\circ} \mathrm{C}$ ) para germinar. Su modo de germinación es faneroepígea. Las especies de Bursera sección Bursera, con semillas trivalvadas, presentaron un alto porcentaje de semillas abortivas, como es el caso de las especies del complejo B. simaruba (B. grandifolia y B. longipes). El porcentaje de germinación más alto fue para dos especies de la sección Bullockia; $38 \%$ para B. copallifera, $28 \%$ para $B$. submoniliformis y menos del $5 \%$ para las especies restantes.
Las plántulas de Bursera sección Bursera presentaron raíz axonomorfa, formando tubérculos o engrosamiento durante su crecimiento. El cuello de la raíz es blanco y engrosado en la base. El hipocótilo es cilíndrico y delgado (figuras 2 y 3), ligeramente estriado y lenticelado. En el caso de las plántulas de Bursera sección Bullockia, la raíz es axonomorfa, carece de tubérculo o engrosamiento, y presenta un doblez sigmoidal de hasta $90^{\circ}$ que comienza desde la base del cuello. El cuello de la raíz es blanco y sin engrosamiento. El hipocótilo es cilíndrico y engrosado (figuras 4 y 5), presenta abundantes lenticelas y es muy estriado.

Las hojas cotiledonares son subsésiles y tienen margen entero en todas las especies estudiadas. En cuanto a la morfología, se consideraron importantes dos estados de carácter: (1) la forma trilobada que está representada en las especies de la sección Bullockia y las especies del complejo B. simaruba, las cuales pertenecen a la sección Bursera, y (2) la forma multilobada que se presenta en las especies de 'cuajiotes' amarillos y rojos de la sección Bursera.

En cuanto a la morfología de los protófilos, en la sección Bursera se observó la presencia de un pecíolo alado acanalado y cuando hay presencia de raquis, éste es alado. La inserción de los folíolos laterales del protófilo es sésil en $B$. aptera, $B$. lancifolia, $B$. morelensis y subsésil en $B$. schlechtendalii y $B$. grandifolia. Las especies de 'cuajiotes', B. aptera, $B$.

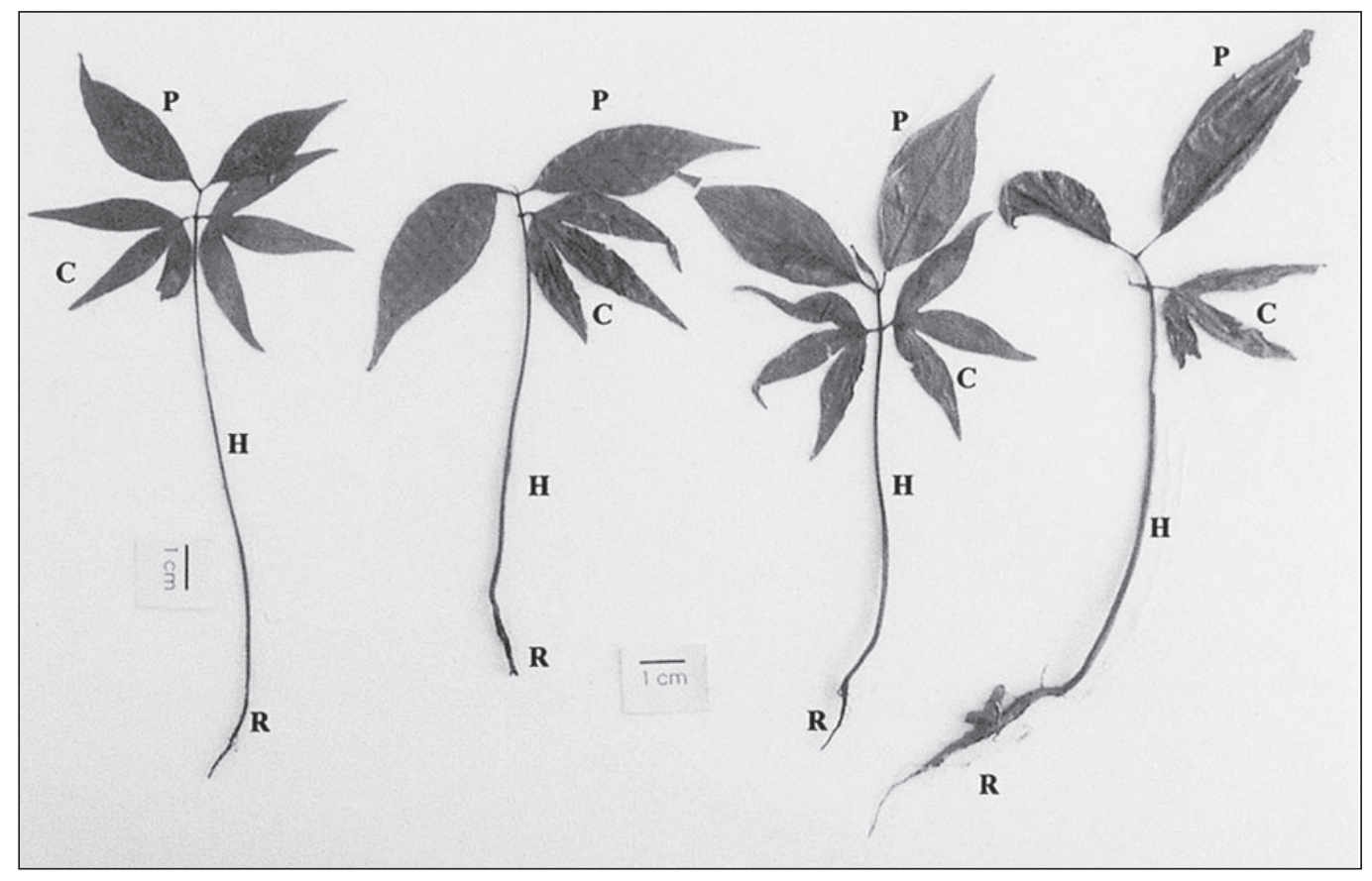

Figura 2. Caracteres de plántulas de Bursera grandifolia: C, hojas cotiledonares trilobadas con lóbulos grandes y anchos; H, hipocótilo delgado; P, protófilos opuestos y unifoliolados con pecíolo acanalado, margen entero y ápice acuminado; R, raíz axonomorfa sin engrosamiento. 


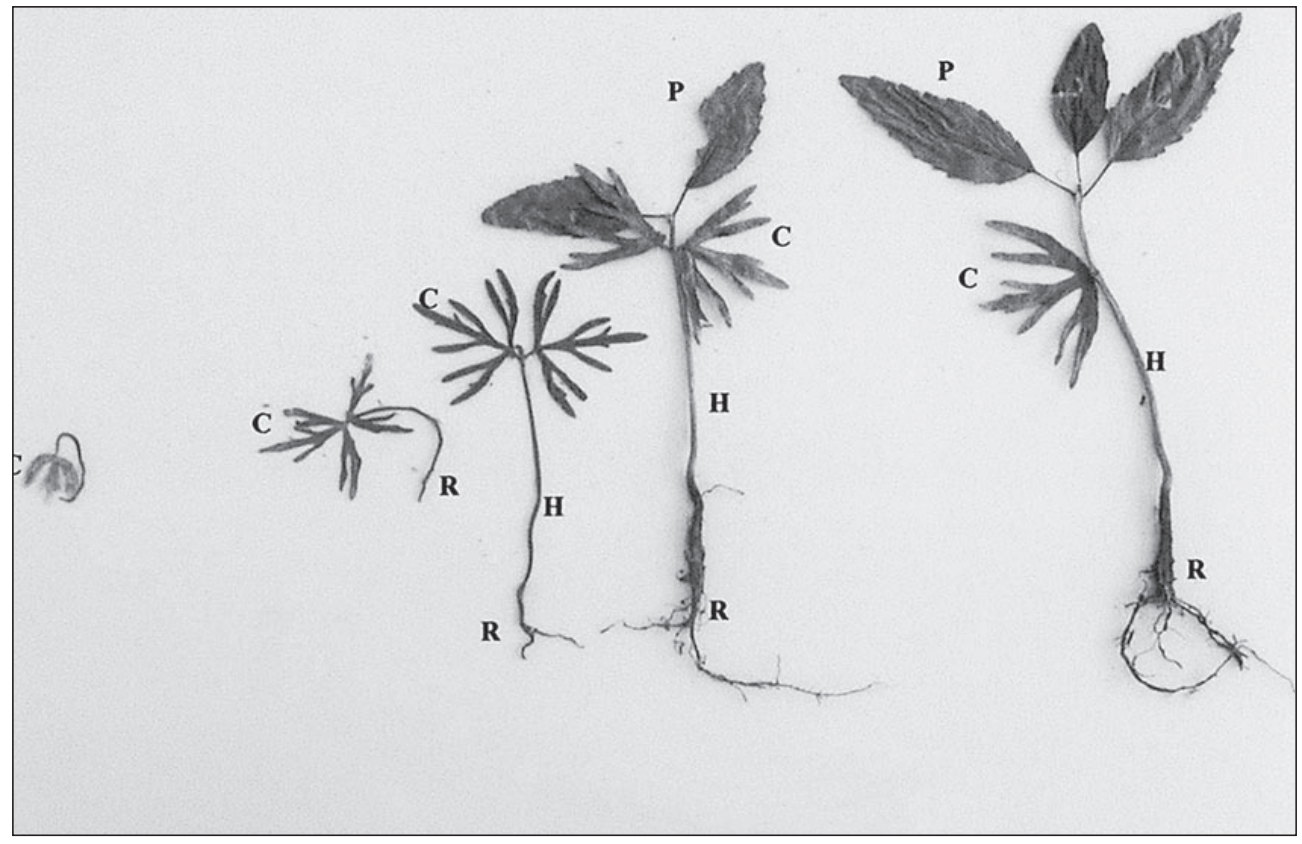

Figura 3. Caracteres de plántulas de Bursera schlechtendalii: C, hojas cotiledonares multilobadas con lóbulos delgados; H, hipocótilo delgado; P, protófilos opuestos y unifoliolados con pecíolo acanalado, margen aserrado; R, radícula axonomorfa con engrosamiento.

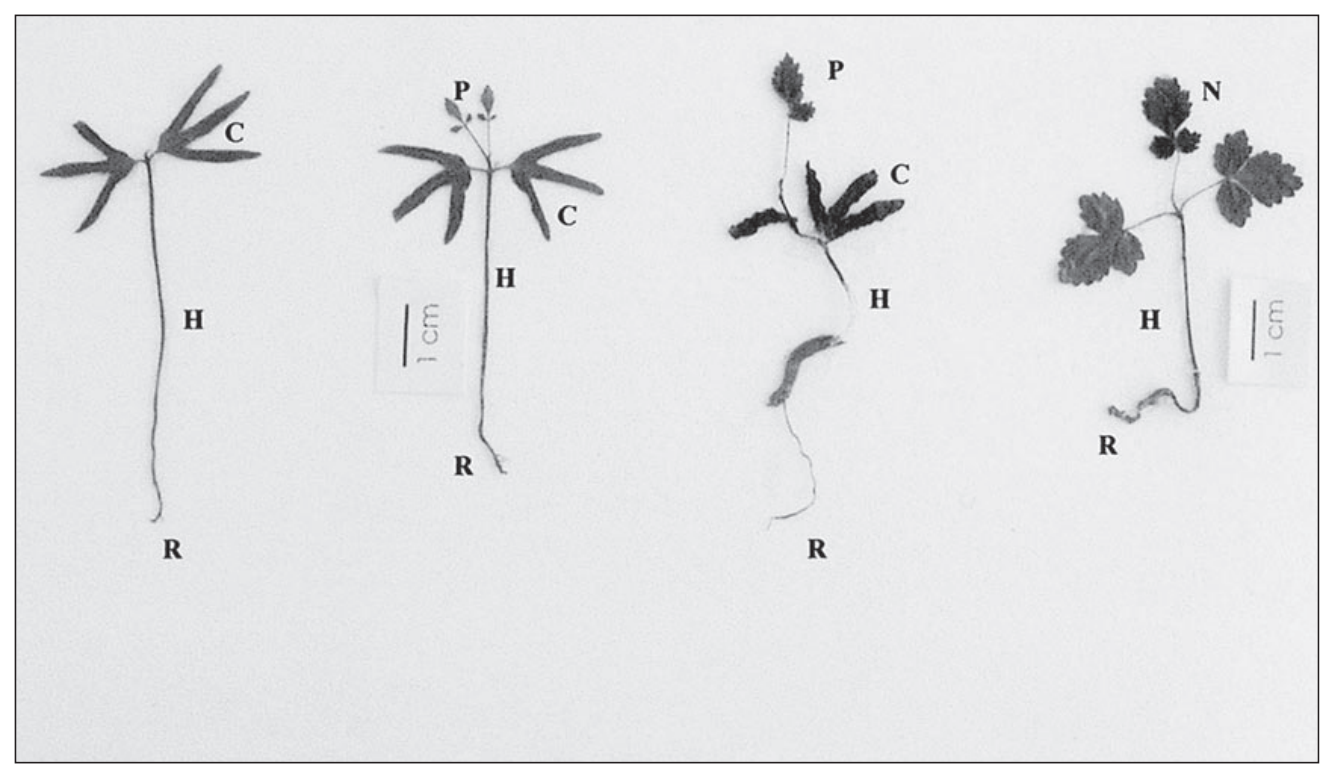

Figura 4. Caracteres de plántulas de Bursera copallifera: C, hojas cotiledonares trilobadas con lóbulos delgados; H, hipocótilo engrosado; P, protófilos opuestos y compuestos, trifoliolados, con pecíolo acanalado, base cuneada y margen aserrado; N, nomófilo compuesto de tres folíolos; R, raíz axonomorfa delgada con doblez sigmoideo. 


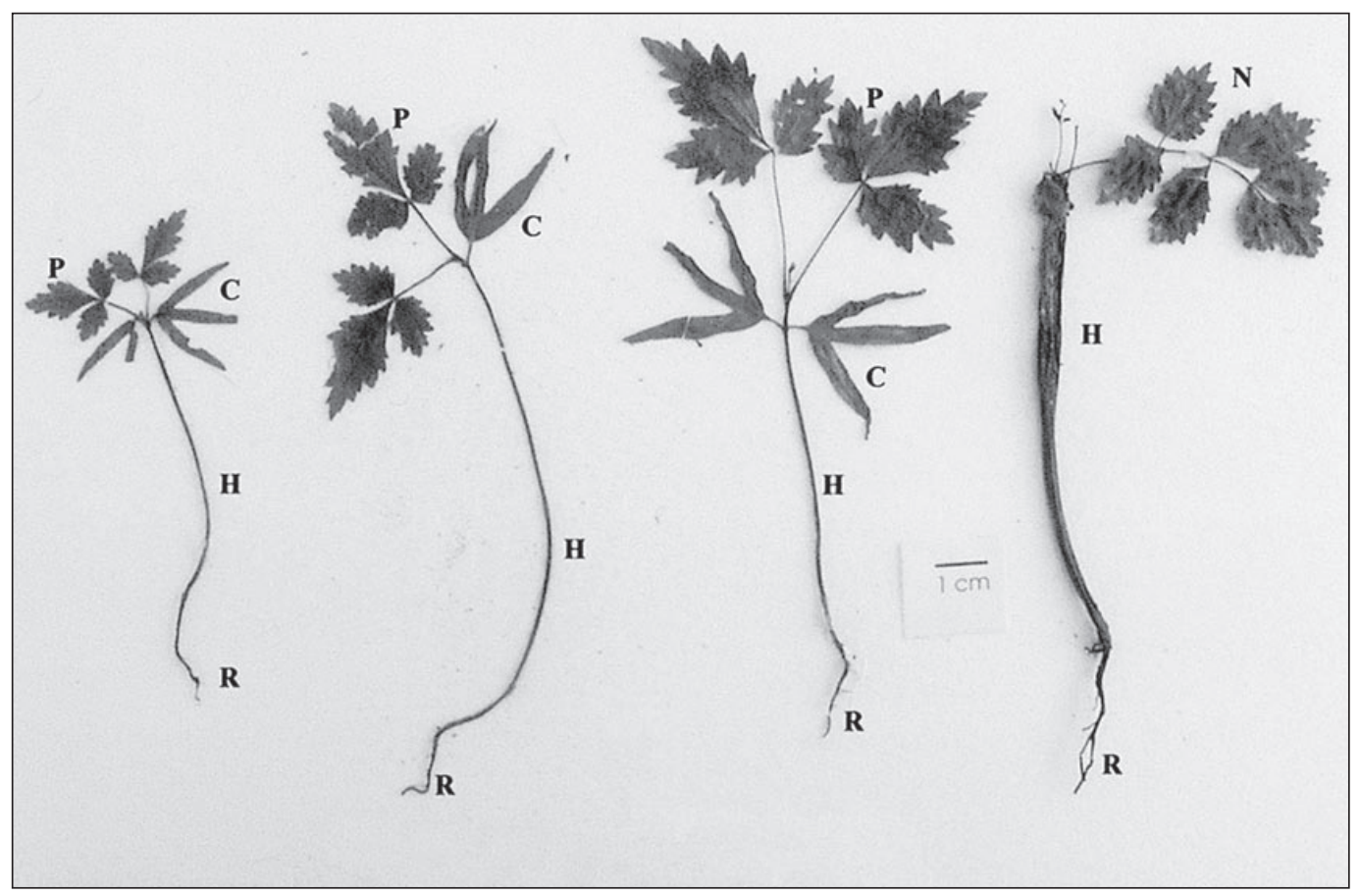

Figura 5. Caracteres de plántulas de Bursera glabrifolia: C, hojas cotiledonares trilobadas con lóbulos delgados; H, hipocótilo engrosado; P, protófilos opuestos trifoliolados, base cuneada y márgenes marcadamente aserrados; N, nomófilo compuesto de siete folíolos; R, raíz axonomorfa delgada.

lancifolia y B. morelensis, presentan plántulas trifolioladas con los folíolos impares sectados. En el caso de $B$. grandifolia y B. longipes (grupo B. simaruba), los protófilos son unifoliolados y con margen entero; para estas dos especies, el tipo de venación es broquidódromo, mientras que en el resto de las especies de la sección Bursera es cladódromo.

Las especies de la sección Bullockia presentaron protófilos trifoliolados, pecíolos alados y acanalados, raquis alado y la inserción de los folíolos sésil. El tipo de venación de los protófilos es broquidódromo.
Los caracteres correspondientes a la forma del folíolo, base, ápice, margen y presencia de tricomas se muestran en los cuadros 1 y 2 .

Se obtuvieron catorce redes de Wagner más parsimoniosas de longitud $(\mathrm{L})=32$ pasos, índice de consistencia $(\mathrm{CI})=$ 0.59 , e índice de retención $(\mathrm{RI})=0.66$. Se seleccionó una de ellas para ilustrar los grupos obtenidos (figura 6): los 'cuajiotes', sustentado por las hojas cotiledonares multilobadas y la venación cladódroma de los protófilos; la sección Bullockia, sustentado por la presencia de un doblez

Cuadro 1. Caracteres y estados de carácter de las especies revisadas.

\begin{tabular}{|c|c|}
\hline Caracteres & Estados de carácter \\
\hline 1. Hojas cotiledonares & trilobadas $(\mathrm{t})$, multilobadas $(\mathrm{m})$ \\
\hline 2. Raíz tuberosa & presente $(1)$, ausente $(0)$ \\
\hline 3. Doblez sigmoidal & presente $(1)$, ausente $(0)$ \\
\hline 4. Hipocótilo engrosado & presente $(1)$, ausente $(0)$ \\
\hline 5. Forma del folíolo & ovada (o), lanceolada (I), linear (n) \\
\hline 6. Tipo de margen & dentado $(\mathrm{d})$, entero $(\mathrm{e})$, aserrado (a) \\
\hline 7. Tipo de base & cuneada $(\mathrm{c})$, cordada $(\mathrm{d})$, redonda $(\mathrm{r})$, oblicua $(\mathrm{o})$ \\
\hline 8. Tipo de ápice & redondeado $(r)$, acuminado $(a)$, retuso $(e)$ \\
\hline 9. Forma del raquis & alado (a), desnudo (d) \\
\hline 10. Tricomas simple sobre los folíolos & presente $(1)$ ausente $(0)$ \\
\hline 11. Tricomas glandulares sobre los folíolos & presente $(1)$, ausente $(0)$ \\
\hline 12. Tipo de nervadura & cladódroma (c), broquidódroma (b), semicraspedódroma (s). \\
\hline
\end{tabular}


Cuadro 2. Matrices de estados de carácter de cada una de las especies. Los símbolos del cuadro superior (a) corresponden a los del cuadro 1; el inferior (b) contiene la matriz codificada que fue analizada con Hennig86. A la derecha de cada especie se indica entre paréntesis el grupo al que pertenece, según la figura 1

(a)

\begin{tabular}{|c|c|c|c|c|c|c|c|c|c|c|c|c|}
\hline \multirow[t]{2}{*}{ Especies } & \multicolumn{12}{|c|}{ Caracteres } \\
\hline & 1 & 2 & 3 & 4 & 5 & 6 & 7 & 8 & 9 & 10 & 11 & 12 \\
\hline \multicolumn{13}{|l|}{ B. sección Bursera } \\
\hline B. aptera (4) & $\mathrm{m}$ & 1 & 0 & 0 & $\mathrm{o}$ & $\mathrm{D}$ & c & $\mathrm{r}$ & a & 0 & 0 & c \\
\hline B. lancifolia (2) & $\mathrm{m}$ & 1 & 0 & 0 & I & $\mathrm{D}$ & c & $r$ & $\mathrm{a}$ & 0 & 1 & c \\
\hline B. schlechtendalii (4) & $\mathrm{m}$ & 1 & 0 & 0 & $\mathrm{o}$ & A & $\mathrm{r}$ & e & $\mathrm{a}$ & 0 & 0 & c \\
\hline B. morelensis (3) & $\mathrm{m}$ & 1 & 0 & 0 & $\mathrm{n}$ & $\mathrm{E}$ & $\mathrm{c}$ & $\mathrm{r}$ & $\mathrm{a}$ & 0 & 0 & $\mathrm{C}$ \\
\hline B. longipes (1) & $\mathrm{t}$ & 1 & 0 & 0 & o & $\mathrm{E}$ & d & $\mathrm{a}$ & 0 & 0 & 0 & b \\
\hline B. grandifolia (1) & $t$ & 1 & 0 & 0 & $\mathrm{o}$ & $\mathrm{E}$ & $\mathrm{c}$ & a & 0 & 1 & 1 & b \\
\hline \multicolumn{13}{|l|}{ B. sección Bullockia } \\
\hline B. bicolor (5) & $\mathrm{t}$ & 0 & 1 & 1 & o & $\mathrm{D}$ & $\mathrm{o}$ & $\mathrm{r}$ & $\mathrm{a}$ & 1 & 1 & $\mathrm{~s}$ \\
\hline B. submoniliformis (5) & $t$ & 0 & 1 & 1 & $\mathrm{o}$ & $\mathrm{D}$ & $\mathrm{o}$ & $\mathrm{r}$ & $\mathrm{a}$ & 1 & 0 & $\mathrm{~s}$ \\
\hline B. copallifera (5) & $t$ & 0 & 1 & 1 & $\mathrm{o}$ & $\mathrm{D}$ & $\mathrm{C}$ & $\mathrm{r}$ & $\mathrm{a}$ & 1 & 1 & $\mathrm{~s}$ \\
\hline B. glabrifolia (6) & $\mathrm{t}$ & 0 & 1 & 1 & $\mathrm{o} / \mathrm{l}$ & $\mathrm{D}$ & C & $r$ & $\mathrm{a}$ & 1 & 0 & $\mathrm{~s}$ \\
\hline
\end{tabular}

(b)

\begin{tabular}{|c|c|c|c|c|c|c|c|c|c|c|c|c|}
\hline \multirow[t]{2}{*}{ Especies } & \multicolumn{12}{|c|}{ Caracteres } \\
\hline & 1 & 2 & 3 & 4 & 5 & 6 & 7 & 8 & 9 & 10 & 11 & 12 \\
\hline \multicolumn{13}{|l|}{ B. sección Bursera } \\
\hline B. aptera (4) & 1 & 1 & 0 & 0 & 0 & 0 & 0 & 0 & 0 & 0 & 0 & 1 \\
\hline B. lancifolia (2) & 1 & 1 & 0 & 0 & 1 & 0 & 0 & 0 & 0 & 0 & 1 & 1 \\
\hline B. schlechtendalii (4) & 1 & 1 & 0 & 0 & 0 & 2 & 1 & 2 & 0 & 0 & 0 & 1 \\
\hline B. morelensis (3) & 1 & 1 & 0 & 0 & 2 & 1 & 0 & 0 & 0 & 0 & 0 & 1 \\
\hline B. longipes (1) & 0 & 1 & 0 & 0 & 0 & 2 & 2 & 1 & 1 & 0 & 0 & 0 \\
\hline B. grandifolia (1) & 0 & 1 & 0 & 0 & 0 & 2 & 0 & 1 & 1 & 1 & 1 & 0 \\
\hline \multicolumn{13}{|l|}{ B. sección Bullockia } \\
\hline B. bicolor (5) & 0 & 0 & 1 & 1 & 0 & 0 & 3 & 0 & 0 & 1 & 1 & 2 \\
\hline B. submoniliformis (5) & 0 & 0 & 1 & 1 & 0 & 0 & 3 & 0 & 0 & 1 & 0 & 2 \\
\hline B. copallifera (5) & 0 & 0 & 1 & 1 & 0 & 0 & 0 & 0 & 0 & 1 & 1 & 2 \\
\hline B. glabrifolia (6) & 0 & 0 & 1 & 1 & 1 & 0 & 0 & 0 & 0 & 1 & 0 & 2 \\
\hline
\end{tabular}

sigmoideo de la radícula, hipocótilo engrosado lenticelado y estriado, y venación semicraspedódroma de los protófilos; las especies del complejo B. simaruba forman un grupo sustentado por hojas con folíolos de margen entero, ápice acuminado y raquis desnudo. Los cuajiotes, junto con la sección Bullockia, forman un grupo sustentado por tres caracteres: margen del protófilo aserrado o dentado, ápice redondeado u obtuso y raquis alado.

\section{Discusión}

La germinación dependió fundamentalmente del estado de madurez de las semillas, por lo que se recomienda recolectar los frutos con pseudoarilos expuestos y coloreados, para asegurar que no exista gran cantidad de semillas abortivas, como lo reporta Johnson (1992). Los porcentajes de germinación siempre serán bajos (menos de 50\%) debido a la frecuencia de semillas vanas que presentan varias especies.

Es difícil establecer el límite de la fase de plántula en estas especies, ya que permanecen en este estadio por un largo periodo, incluso por varios años. Las plántulas se tornan rápidamente leñosas desde el primer año, son caducifolias, con metabolismo lento, y posiblemente pasan por un estadio juvenil de varios años antes de presentar las características de la planta adulta. De tal manera, consideramos para este estudio a la fase de plántula desde que emerge por completo de la testa hasta la aparición de la primera nomófila, aun cuando las características de una planta adulta típica hayan o no aparecido.

Con base en las descripciones morfológicas de las plántulas se pueden diferenciar como estados excluyentes en estas especies estudiadas al tipo de radícula (con o sin tubérculo) y el hipocótilo (engrosado o delgado).

La distribución de los caracteres sobre la red de Wagner diagnostican tres grandes grupos (figura 6): especies del 'Complejo B. simaruba' (clado 1), especies de la sección Bullockia (clado 2) y el de las especies de 'cuajiotes' (clado 3). Esto coincide, en general, con los resultados de la filogenia obtenida con caracteres moleculares (Becerra y Venable, 1999).

El grupo de los cuajiotes, sugerido por Toledo-Manzur (1982) se diagnostica por la presencia de la hoja cotiledonar multilobada. Al respecto, Rzedowski y Kruse (1979) 


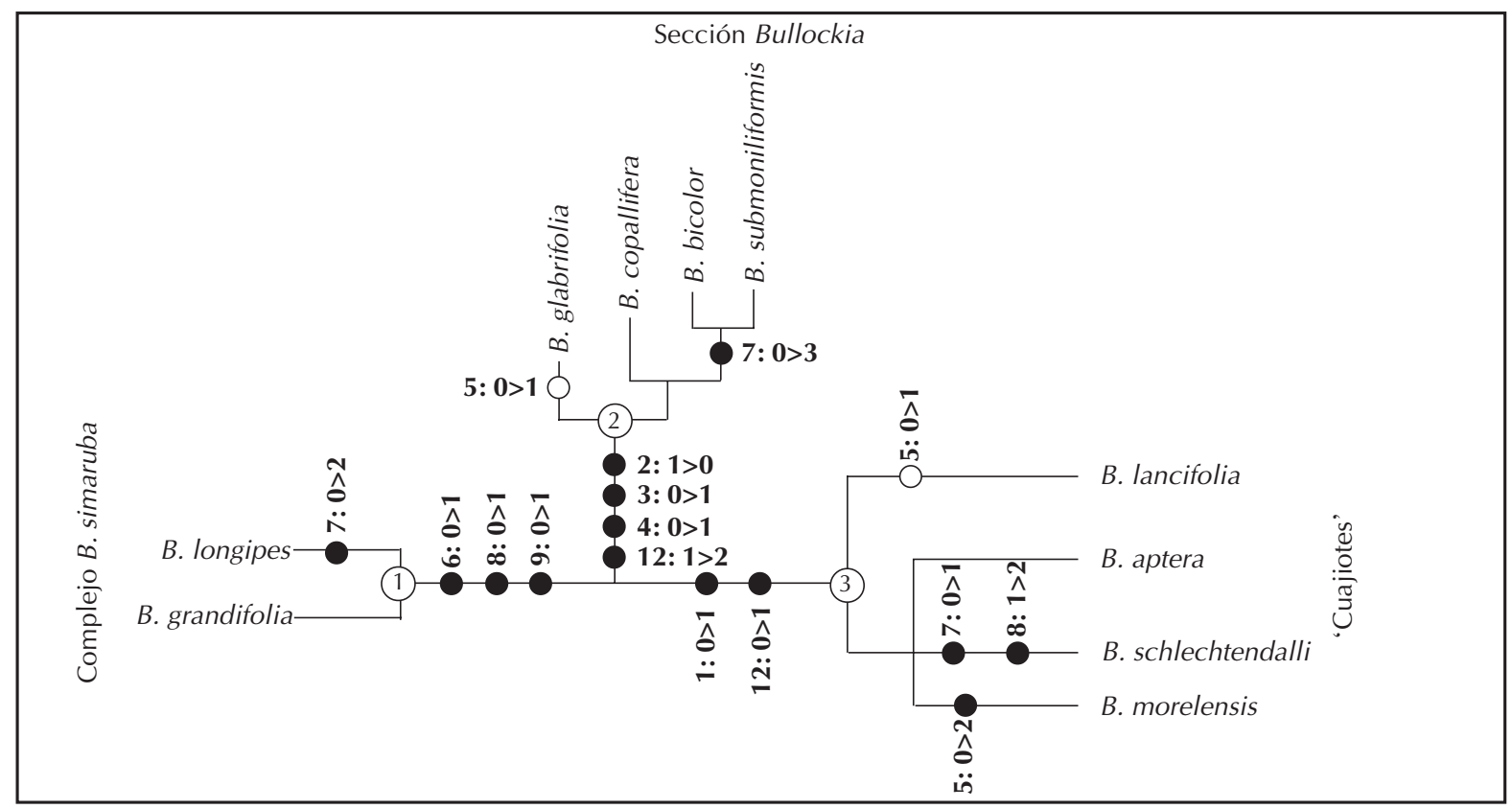

Figura 6. Una de las 14 redes de Wagner más parsimoniosas obtenidas en el análisis: $\mathrm{L}=32, \mathrm{CI}=0.59, \mathrm{RI}=0.66$. La red, los caracteres y la distribución de sus estados fueron dibujados mediante el programa Winclada (Nixon, 1999) y redibujados como una red. Ver los cuadros 1 y 2 para la simbología de los caracteres.

propusieron la hipótesis de que tal vez la hoja cotiledonar trilobada originó a la multilobada.

Los caracteres de plántula aportan algunos datos adicionales para interpretar las series de transformación de algunos caracteres de la planta adulta. Por ejemplo, encontramos que el margen entero de algunas especies de 'cuajiotes' (B. aptera, B. morelensis, B. schlechtendalii) y de la sección Bullockia ( $B$. bicolor) no tienen el mismo origen que el margen entero de los folíolos de las especies $B$. grandifolia y $B$. longipes (grupo $B$. simaruba). Éstos tienen margen entero tanto en estadio de plántula como en el adulto, mientras que en las especies de 'cuajiotes' se observa que los folíolos del protófilo tienen margen dentado o aserrado, el cual posteriormente se puede transformar a entero en la planta adulta. Incluso es posible observar esta misma sucesión durante la foliación de un individuo adulto. En el campo, se observaron individuos de B. aptera y B. bicolor cuyas primeras hojas de renuevo (particularmente las de las ramas inferiores) eran marcadamente dentadas o crenadas, para dar lugar posteriormente a hojas de margen entero. Es más, la condición revoluta del margen de $B$. bicolor disimula algunos dientes rudimentarios sobre un borde aparentemente entero.

Por otra parte, aunque el raquis alado es más frecuente en los individuos adultos de las especies de la sección Bullockia, se observó que también es una condición frecuente en los protófilos de plántulas de cuajiotes. Sin embargo, el raquis alado de los cuajiotes siempre es entero y delgado, mientras que las especies de la sección Bullockia muestran un raquis generalmente más amplio y crenado, sobre todo hacia el estado adulto.

Otro carácter que separa a los tres grupos fue el patrón de venación de los folíolos de los protófilos, el cual fue claramente cladódromo en las especies de cuajiotes, mientras que en las dos especies del complejo B. simaruba fue broquidódromo y en las especies de la sección Bullockia fue semicraspedódromo.

La estructura de la figura 6 es sólo una primera hipótesis sobre la taxonomía de plántulas en este género y debe ser sometida a prueba, extendiendo el estudio al resto de las especies y por la adición de nuevos caracteres no explorados.

Las características morfológicas de las plántulas establecen distinciones exclusivas para cada una de las dos secciones del género y estos caracteres pueden utilizarse para su identificación. La morfología de folíolos presenta una secuencia heteroblástica durante el desarrollo, que proporciona criterios para establecer las series de transformación de algunos caracteres de las plantas adultas. Algunos caracteres no cambian desde el estado de plántula al adulto, como el margen entero y el ápice acuminado de las especies del complejo B. simaruba. Por ello, la morfología de plántulas apoya la consideración de algunos grupos como los ‘cuajiotes' y los 'mulatos', que hasta ahora han sido referidos como complejos de especies o grupos tentativos. Así también, se apoya a la sección Bullockia. 


\section{Agradecimientos}

Agradecemos la revisión crítica y sugerencias hechas al manuscrito por Teresa Terrazas, María Eugenia Fraile, Juan José Morrone, Isolda Luna, José Luis Villaseñor y un revisor anónimo. David Espinosa agradece el apoyo de DGAPA para la realización de su estancia sabática en la Facultad de Ciencias. Se agradece el apoyo de los proyectos IN205799 (DGAPA-PAPIIT), 31879-N y 36488 (CONACyT).

\section{Literatura citada}

Andrés-Hernández A.R. 1997. Análisis morfológico en plántulas de 11 especies del género Bursera Jacq. ex L. Tesis de Licenciatura, Facultad de Estudios Superiores Zaragoza, Universidad Nacional Autónoma de México, México, D.F., 53 pp.

Andrés-Hernández A.R. 2001. Análisis y descripción de estructuras foliares de especies del género Bursera Jacq. ex L. que se distribuyen en la Cuenca de Río Balsas. Tesis de Maestría en Ciencias, Facultad de Ciencias, Universidad Nacional Autónoma de México, México, D.F., 86 pp.

Bell A.D. 1993. Plant Form: An Illustrated Guide to Flowering Plant Morphology. Oxford University Press, Oxford.

Becerra J.X. y Venable L. 1999. Nuclear ribosomal DNA phylogeny and its implications for evolutionary trends in Mexican Bursera (Burseraceae). American Journal of Botany 86:10471057.

Bullock A.A. 1936. Contributions to the flora of tropical America: xxxvii. Notes on the Mexican species of the genus Bursera. Kew Bulletin 8:346-387.

Daly D.C. 1993. Notes on Bursera in South America, including a new species. Studies in Neotropical Burseraceae VII. Brittonia 45:240-246.

Duke J.A. y Polhill R.M. 1981. Seedling of Leguminosae. En: Polhill R.M. y Raven P.H. Eds. Advances in Legume Systematics. Part 2. The Royal Botanic Gardens, Kew, 941-949.
Engler A. 1883. Burseraceae. En: Engler A. y Prantl K. Eds. Die Natürtichen Pflanzenfamilien. Band, 405-456.

Farris J.S. 1988. Hennig86. Versión 1.5. Editado por el autor. Port Jefferson, Nueva York.

Font Quer P. 1993. Diccionario de Botánica. Labor, Barcelona.

Gillett J.B. 1980. Commiphora (Burseraceae) in South America and its relationships to Bursera. Kew Bulletin 34:569-587.

Hickey L.J. 1974. Clasificación de la arquitectura de las hojas de dicotiledóneas. Boletín de la Sociedad Argentina de Botánica 16:1-26.

Johnson M.B. 1992. The genus Bursera (Burseraceae) in Sonora, Mexico and Arizona, U.S.A. Desert Plants 10:126-144.

McVaugh R. y Rzedowski J. 1965. Synopsis of the genus Burseral. in western Mexico, with notes on the material of Bursera collected by Sessé \& Mociño. Kew Bulletin 18:317-382.

Moreno N.P. 1987. Glosario Botánico Ilustrado. Instituto Nacional de Investigaciones sobre Recursos Bióticos, C.E.C.S.A., México, D.F.

Nixon K.C. 1999. WINCLADA para IBM PC, Ver. 0.9.99.unam21. Versión Beta, distribuido por el autor.

Nixon K.C. y Carpenter J. 1993. On outgroups. Cladistics 9:413426.

Parra G.P. 1984. Estudio de la morfología externa de plántulas de Calliandra gracilis, Mimosa albida, Mimosa arenosa, Mimosa camporum y Mimosa tenuiflora. Revista de la Facultad de Agronomía (Maracay) XIII:311-350.

Rzedowski J. 1968. Notas sobre el género Bursera (Burseraceae) en el estado de Guerrero (México). Anales de la Escuela Nacional de Ciencias Biológicas IPN 17:17-36.

Rzedowski J. y Kruse H. 1979. Algunas tendencias evolutivas en Bursera (Burseraceae). Taxon 28:103-116.

Toledo-Manzur C.A. 1982. El género Bursera (Burseraceae) en Guerrero (México). Tesis de Licenciatura, Facultad de Ciencias, Universidad Nacional Autónoma de México, México, D.F., 182 pp.

Thulin M. y Warfa A.M. 1986. The frankincense trees (Boswellia spp., Burseraceae) of northern Somalia and southern Arabia. Kew Bulletin 42: 487-500.

Apéndice 1. Especies de las que se recolectaron semillas para el estudio de las plántulas.

Bursera aptera Ramírez; Puebla: Mpio. de Chiautla, $3 \mathrm{~km}$ al NE de Chiautla sobre el camino a San Francisco, 98 34.76' O, $18^{\circ} 19.75^{\prime} \mathrm{N}, 1235$ m snm, Andrés, R. 12 y D. Espinosa (FEZA). Bursera bicolor Engl.; Puebla: Mpio. de Chietla, 1 km al N de Tlancualpican, sobre el camino a El Limón, cerca del Río Nexapa, $98.70^{\circ} \mathrm{O}, 18.44^{\circ} \mathrm{N}, 1000 \mathrm{~m} \mathrm{snm}$, Andrés, $R$. 36 y D. Espinosa (FEZA). Bursera copallifera (DC.) Bullock; Puebla: Mpio. de Chietla, $1 \mathrm{~km}$ al N de Tlancualpican, sobre el camino a El Limón, cerca de un recodo del Río Nexapa, 98 41' O, 18² 27.03' N, 1102 m snm, Andrés, R. 24 y D. Espinosa (FEZA). Bursera glabrifolia Engl.; Puebla: Mpio. de Chiautla, 3 km al NE de Chiautla, sobre el camino a San Francisco, 98 $35.49^{\prime}$ O, $18^{\circ} 19.15^{\prime} \mathrm{N}, 1052 \mathrm{~m}$ snm, Andrés, R. 28 y D. Espinosa (FEZA). Bursera grandifolia (Schltdl.) Engl.; Puebla: Mpio. de Teotlalco, $1.5 \mathrm{~km}$ al SO de Teotlalco, 98 34.76' O, 18 19.75', $1235 \mathrm{~m} \mathrm{snm}$, Andrés, $R .18$ y D. Espinosa, (FEZA). Bursera lancifolia (Schltdl.) Engl. Puebla: Mpio. de Teotlalco, $1.5 \mathrm{~km}$ al SO de Teotlalco, 98 34.76' O, $18^{\circ} 19.75 \mathrm{~N}, 1235 \mathrm{~m} \mathrm{snm}$, Andrés, R. 15 y D. Espinosa (FEZA). Bursera longipes (Rose) Standl.; Puebla: Mpio. de Chietla, 1 km al N de Tlancualpican, sobre el camino a El Limón, cerca de un recodo del Río Nexapa, $98.70^{\circ} \mathrm{O}, 18.44^{\circ} \mathrm{N}, 1000 \mathrm{~m} \mathrm{snm}$. Andrés, R. 9 y D Espinosa (FEZA). Bursera morelensis Ramírez; Puebla: Mpio. de Chietla, Barranca 'El Almagre', $1.5 \mathrm{~km}$ al E de Tlancualpican, $98.68^{\circ} \mathrm{O}, 18.42^{\circ} \mathrm{N}, 1100 \mathrm{~m}$ snm. Andrés, R. 30 y D. Espinosa (FEZA). Bursera schlechtendalii Engl.; Puebla: Mpio. de Chietla, en orilla de recodo del Río Nexapa, al S de Tlancualpican, $98.68^{\circ} \mathrm{O}, 18.42^{\circ} \mathrm{N}, 1100 \mathrm{~m} \mathrm{snm}$, Andrés, $R .19$ y $D$. Espinosa (FEZA). Bursera submoniliformis Engl.; Puebla: Mpio. de Chietla, $1 \mathrm{~km}$ al $\mathrm{N}$ de Tlancualpican, en el camino a El Limón, cerca del Río Nexapa, $98.70^{\circ} \mathrm{O}, 18.44^{\circ} \mathrm{N}, 1000 \mathrm{~m}$ snm. Andrés, R. 10 y D. Espinosa (FEZA). 